\title{
Isolation of a new marker and conserved sequences close to the DiGeorge syndrome marker HP500 (D22S134)
}

R Wadey, S Daw, A Wickremasinghe, C Roberts, D Wilson, J Goodship, J Burn, $S$ Halford, P J Scambler

\begin{abstract}
End fragment cloning from a YAC at the D22S134 locus allowed the isolation of a new probe HD7k. This marker detects hemizygosity in two patients previously shown to be dizygous for D22S134. This positions the distal deletion breakpoint in these patients to the sequences within the YAC, and confirms that HD7k is proximal to D22S134. In a search for coding sequences within the region commonly deleted in DGS we have identified a conserved sequence at D22S134. Although no cDNAs have yet been isolated, genomic sequencing shows a short open reading frame with weak similarity to collagen proteins.
\end{abstract}

(f Med Genet 1993;30:818-21)

Hemizygosity for a region within $22 \mathrm{q} 11$ can be associated with a wide range of phenotypes from no detectable abnormality to severe dysmorphology. The clinical diagnoses given in these cases have included DiGeorge syndrome (DGS), ${ }^{1-7}$ velocardiofacial ${ }^{8-10}$ (Shprintzen) syndrome (VCFS), Noonan syndrome, ${ }^{11}$ conotruncal face anomaly, and familial congenital heart defect. ${ }^{1213}$ In these cases one or more of the following abnormalities may be observed: absent or hypoplastic thymus, absent or hypoplastic parathyroids, conotruncal heart defect, and cleft palate and abnormal facies. Besides these main features many other defects have been reported in association with DGS and VCFS. ${ }^{14-19}$ Several lines of evidence point to the major abnormalities having a similar underlying embryological basis, namely a deficiency in the neural crest's contribution to the development of the branchial arch/pharyngeal pouch system. ${ }^{20-23}$

We have previously reported the marker HP500 for the locus D22S134 which is hemizygous in most cases of DGS/VCFS. This locus was also used to show deletions in the familial congenital heart disease study. Although HP500 is not deleted in all cases of DGS known to have chromosome 22 abnormalities, the possibility that DGS is a contiguous gene deletion syndrome ${ }^{24}$ led us to attempt the identification of potential coding sequences in the region. Our previous mapping studies had indicated that HP500 might detect cross hybridising sequences in rodents. This was investigated further using 'zoo' blots and DNA sequencing.

We have previously described a YAC isolated with HP500 and the isolation of cosmids corresponding to the terminal sequences of the YAC insert; D0832 is one of these cosmids. The terminal sequence cosmids have been orientated by $\mathrm{FISH},{ }^{25}$ with D0832 mapping proximal to sc4.1, a cosmid containing HP500. ${ }^{26}$ In this work we report the isolation of a single copy probe from D0832 for use as a Southern hybridisation probe, and the detection of potential conserved sequences at HP500.

\section{Materials and methods}

DNA PROBES, SUBCLONING, AND SEQUENCING Cosmid D0832 has been described previously and was isolated from library ICRF library 106(L4/FS22) constructed by D Nizetic. Cosmid DNA was digested with the enzyme HindIII and fragments shotgunned into HindIII digested pBluescript vector. ${ }^{27}$ Subclone inserts were isolated from LMP agarose gels, labelled by random oligonucleotide priming, ${ }^{28}$ and hybridised to strips of HindIII digested human genomic DNA. In this way single copy sequences could be identified. Similarly, SauIIIa fragments of HP500 were shotgunned into M13mp18 for sequencing, which was conducted using a kit (Sequenase II, USB). Some sequence was also obtained from the original HP500 clone in pUC13 using universal primers and an automated ALF sequencer (Pharmacia). XV2c is a genomic clone from chromosome 7 close to $\mathrm{CFTR}^{29}$ and was used as a control probe in quantitative Southern hybridisation experiments.

SOUTHERN HYBRIDISATION

Genomic DNA from a variety of species was digested with EcoRI and Southern blotted according to standard procedures. HP500 was labelled by random oligonucleotide priming and hybridised to the resulting 'zoo' blot. The filter was washed at varying stringencies and the results are shown in fig 1.

Quantitation of Southern hybridisations with probe HD7k was conducted according to our previously published protocol. ${ }^{6}$ However, in place of autoradiography and densitometry a Molecular Dynamics phosphorimager was used to quantitate hybridisation signals on the filter. The Molecular Dynamics Imagequant software was used throughout. This system eliminates those errors secondary to the nonlinear response of film to radiation intensity. Signal strength ratios were calculated as described previously ${ }^{6}$ and as shown in table 1 . 


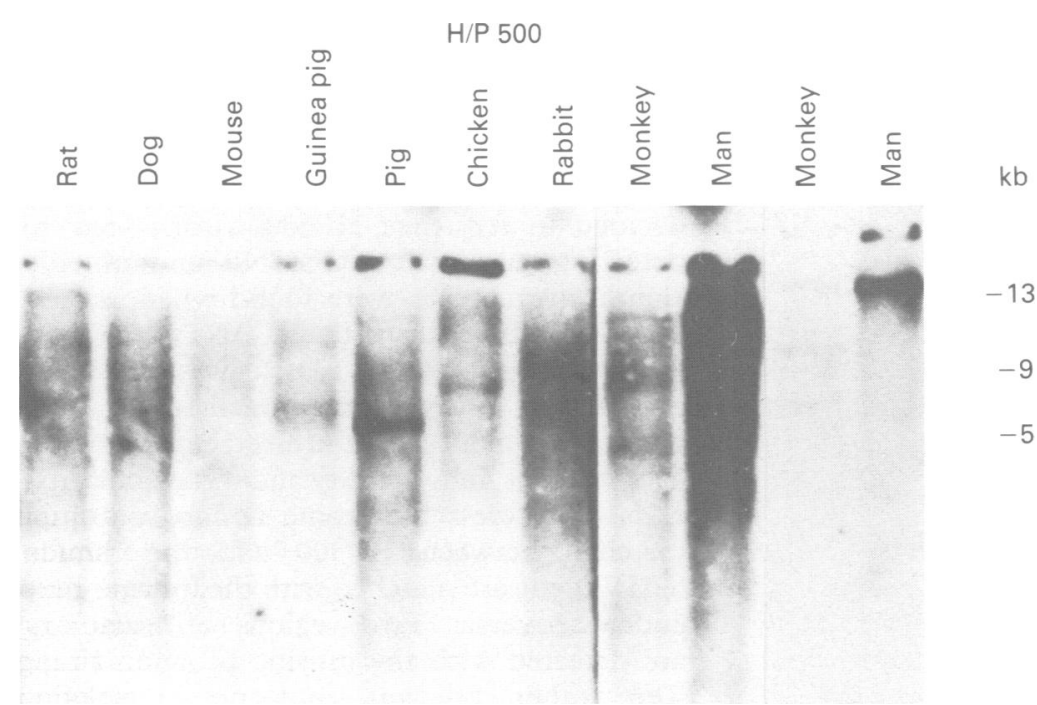

Figure 1 HP500 detects potentially conserved sequences. EcoRI digested genomic $D N A$ was hybridised with HP500 and the filter washed at $1 X S S C / 0 \cdot 1 \% S D S, 65^{\circ}$ initially, then at $0.1 \times S S C$ to increase the visibility of fragments in the human and monkey lanes. Sizes given are determined from a 1 kb ladder which was run alongside the genomic $D N A$. bryo and human fetal brain libraries were screened, but no positives were detected. Therefore, we initiated DNA sequencing of HP500 in a search for open reading frames. Sequencing of SauIIIa shotgun subclones of HP500 yielded no undoubtedly significant database homologies, but one potential open reading frame with borderline homology to various collagen $\alpha$ chains was found (Poisson $\mathrm{p}=0.0015$ under BLAST versus the procollagen $\alpha 2$ (IV) chain precursor) (table 2).

\section{Discussion}

Despite the advent of FISH based diagnosis for DGS/VCFS there is still a need for quantitative Southern analysis in cases where only stored blood samples are available, or where a laboratory does not have access to the relevant cytogenetic facilities. Single copy probes useful for Southern analysis may also be used in chromosome mapping experiments, for instance, in screening genomic libraries. Since our previous experiments had allowed us to orientate a YAC containing the HP500 marker, ${ }^{25}$ and a gap in our genomic clone contig exists proximal to this YAC, we decided to subclone the cosmid D0832 which lies at the proximal end of the YAC. Marker HD7k was isolated and shown to be deleted in several previously untested patients with DGS and VCFS.

Patients known to be dizygous for HP500 were also examined with HD7k, for example, patient NY9 who is hemizygous for the more proximal marker $22.71 .^{10}$ The patient's affected mother NY10 was also incuded in the analysis. Both samples were frozen, anticoagulated blood and therefore FISH analysis was not possible. Both mother and daughter were found to be hemizygous for HD7k indicating that, at least in some cases, HD7k is a more sensitive marker for hemizygosity than HP500. Additionally, it can be inferred that the distal deletion breakpoint in these subjects can be localised to the HP500-HD7k interval, that is, within the TM-YAC. Attempts to clone the sequences at the breakpoint are underway as we are interested in determining whether there are any particular sequence motifs associated with chromosome breakage within 22q11. One possibility is that there is a predisposition to deletion associated with the low copy repeat families present in this region, ${ }^{26}$ with intrachromosomal recombination between such repeats leading to deletions.

It has been postulated that the haploinsufficiencies associated with hemizygosity for $22 \mathrm{q} 11$ are the result of deletion of contiguous genes. We tend to the view that the major features of the condition are the result of haploinsufficiency of one gene (or family of genes) which controls the rostral neural crest's contribution to development. However, it is quite possible that some of the less frequent features of the condition are the result of insufficiency of different genes, or that deletion of additional genes exacerbates the phenotype. Although there is no evidence (as yet) for correlation of extent/position of deletion with 
A
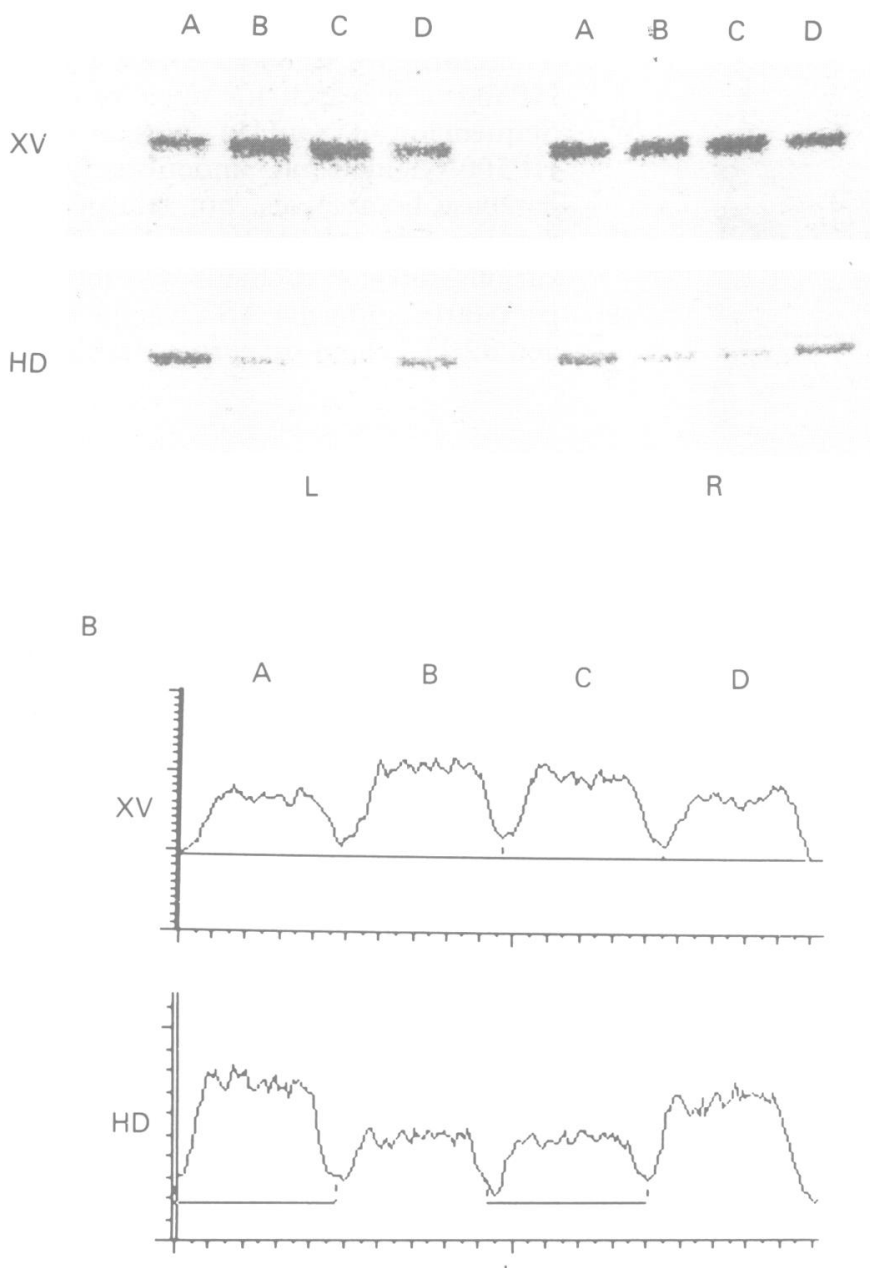

Figure 2 Patients NY9 and NY10 are both hemizygous for HD7k. HindIII digests of control and test DNA were hybridised with $H D 7 k$ and $X V 2 c$ giving single fragments of $8 \mathrm{~kb}$ and $3 \mathrm{~kb}$ respectively. Panel $A$ shows greyscale printer output of scanned images, panel $B$ shows the densitometric profiles obtained for the left hand set of digests $(L)$. Lane $A=$ control; lane $B=N Y 9$; lane $C=N Y 10$; lane $D=$ control.

phenotype, the large size of the deletions associated with DGS (at least $500 \mathrm{~kb}$, and in most cases $2 \mathrm{Mb})^{25}$ is consistent with the involvement of more than one gene.

Previous somatic cell hybrid panels had shown that HP500 cross hybridised with sequences in rodent DNA. This was confirmed by zoo blot analysis which indicated that HP500 detected sequences in a range of mam-

Table 2 Sequence matches of derived HP500 ORF with collagens. Identical amino acids are shown between the two sequences. Conservative matches are designated + . The HP500 sequence is shown above the collagen sequence.

\footnotetext{
Human procollagen $\alpha 2$ (IV) chain $p=0.0013$

HP500 GPAGSQGSTGEVLGAGKVGVSANSPLCPLPRGKRAKPG $\mathrm{GP} \mathrm{G}++\mathrm{G}+\mathrm{GE}+\mathrm{G} \mathrm{G}++\mathrm{ASP}+\mathrm{L}++\mathrm{GR}+\mathrm{PG}$

329 GPDGPRGPKGEAGDPGPPGLPAYSPHPSLAKGARGDPG 366

Murine procollagen $\alpha 2(\mathrm{IV}) \mathrm{p}=0.0015$

Match 1

HP500 GPAGSQGSTGEVLGAGKVGVSANSPLCPLPRGKRAKPG $\mathrm{GP}+\mathrm{G}++\mathrm{G}+\mathrm{GE} \quad \mathrm{G} \mathrm{G} S \mathrm{SP}+\mathrm{L}++\mathrm{G} \mathrm{R}+\mathrm{PG}$

327 GPSGPRGPKGERGEOGPPGPSVYSPHPSLAKGARGDPG
}

Match 2

HP500 GPAGSQGSTGEVLGA

GP $+\mathrm{G}+\mathrm{G}$ GEVLGA

760 GPPGDRGIPGEVLGA 774 mals and chick. Such a result is typical of probes containing conserved sequences potentially encoding a gene. Several screens of mouse embryo and human fetal brain cDNA libraries proved negative and it was therefore decided to sequence HP500 with a view to detecting potential ORFs. No undoubtedly significant matches were found when searching the databases using the BLAST program. ${ }^{28}$ The most significant match was with the procollagen $\alpha 2(\mathrm{IV})$ chain precursor in both human and mouse. Over a stretch of 38 amino acids there is $42 \%$ identity and $68 \%$ similarity. It is of interest that some amino acids not matched between HP500 and the human $\alpha 2$ (IV) gene are matched with the murine gene and vice versa. Two regions of homology are detected with the murine protein. There were other relevant (but non-significant, $\mathrm{p}<1>0.05$ ) matches for other collagens. It is now known that collagens are likely to have roles in development unrelated to chondrogenesis. For instance, collagens can promote avian neural crest migration in vivo ${ }^{30}$ and collagen $\alpha \mathrm{l}$ (II) is expressed transiently in the heart, fetal brain, and neural tube early in mouse embryo development. ${ }^{31}$ It has also been proposed that type II collagen, or a coexpressed matrix molecule, functions as a morphogenetic signal at the epithelial-mesenchymal tissue interface..$^{32}$ Therefore, we are attempting to clone expressed sequences containing this possible collagen-like sequence using RT.PCR of early embryo RNA.

The HD7k/D0832 probes are available for diagnostic use.

We would like to thank Rosalie Goldberg and Robert Shprintzen for sending samples of NY9 and NY10. This work was supported by the MRC(UK), British Heart Foundation, and Action Research.

1 Greenberg F, Elder FFB, Haffner P, Nothrup H, Ledbetter $D$. Cytogenetic findings in a prospective series of patients with DiGeorge anomaly. Am $\mathcal{f}$ Hum Genet 1988;43:60511 .

2 Fibison WJ, Budarf M, McDermid H, Greenberg F, Emanuel BS. Molecular studies of DiGeorge syndrome. $\mathrm{Am} \mathcal{F}$ nuel BS. Molecular studies onet 1990;46:888-95.

3 Scambler PJ, Carey AH, Wyse RKH, et al. Microdeletions within 22q11 associated with sporadic and familial DiGeorge syndrome. Genomics 1991;10:201-6.

4 Carey AH, Claussen U, Ludecke HJ, et al. Interstitial deletions in DiGeorge syndrome detected with microclones from 22q11. Mammalian Genome 1992;3:101-5.

5 Driscoll DA, Budarf ML, Emanuel B. A genetic etiology for DiGeorge syndrome: consistent deletions and microdeletions of 22q11. Am $\mathcal{f}$ Hum Genet 1992;50:924-33.

6 Carey AH, Kelly D, Halford S, et al. Molecular genetic study of the frequency of monosomy 22q11 in DiGeorge syndrome. Am 7 Hum Genet 1992:51:964-70.

7 Desmaze C Scambler P, Prieur M et al Routine diagnosis of $\mathrm{Di}$, of DiGeorge syndrome by fluo

8 Scambler PJ, Kelly D, Williamson R, Goldberg R, Shprintzen $R$. The velo-cardio-facial syndrome is associated with zen $\mathrm{R}$. The velo-cardio-facial syndrome is associated with
chromosome 22 deletions which encompass the DiGeorge chromosome 22 deletions which encompas

9 Driscoll DA, Spinner NB, Budarf ML, et al. Deletions and microdeletions of 22q11.1 in VCFS. Am $\mathcal{f}$ Med Genet microdeletions

10 Kelly D, Goldberg R, Wilson D, et al. Confirmation that the velo-cardio-facial syndrome is associated with haplo insufficiency of genes at chromosome 22q11. Am $\mathcal{f}$ Med Genet 1993;45:308-12.

11 Wilson DI, Bennett Briton S, McKeown C, et al. An individual with Noonan and DiGeorge syndromes with monosomy 22q11. Arch Dis Child 1993;68:187-9.

12 Wilson DI, Cross IE, Goodship JA, et al. DiGeorge syndrome with isolated aortic coarctation and isolated ventricular septal defect in three sibs with a 22q11 deletion of maternal origin. Br Heart f 1991;66:308-12.

13 Wilson DI, Goodship JA, Burn J, Cross IE, Scambler PJ. 
Deletions within chromosome $22 \mathrm{q} 11$ in familial congenital heart disease. Lancet 1992;340:573-5.

14 Freedom RM, Rosen FS, Nadas AS. Congenital cardiovascular disease and anomalies of the third and fourth pharyngeal pouch. Circulation 1992;46:165-72.

15 Moerman P, Goddeeris P, Lauwerijns J, van der Hauwaert LG. Cardiovascular malformations in DiGeorge syndrome (congenital absence or hypoplasia of the thymus) Br Heart $\mathcal{F} 1980 ; 44: 452-9$.

16 Moerman P, Dumoulin M, Lauweryns J, van der Hauwaert LG. Interrupted right aortic arch in DiGeorge syndrome. Br Heart $₹$ 1987;58:274-8.

17 Muller W, Peter HH, Wilken M, et al. The DiGeorge syndrome I. Clinical evaluation and course of partial and complete forms of the syndrome. Clin Immunol Immunopathol 1988;147:496-502.

18 Shprintzen RJ. Velo-cardio-facial syndrome. In: Buyse MA, ed. Birth defects encyclopedia. MA: Dover, 1990:1744-5.

19 Goldberg R, Motzkin B, Marion R, Scambler PJ, Shprintzen R. Velo-cardio-facial syndrome. Am $\mathcal{f}$ Med Genet 1993;45:313-19.

20 Van Mierop LHS, Kutsche LM. Cardiovascular anomalies in DiGeorge syndrome and importance of neural crest as a possible pathogenic factor. Am 7 Cardiol 1986;58:133-7.

21 Bockman DE, Kirby ML, Dependence of thymus development on derivatives of the neural crest. Science ment on derivativ

22 Besson WT, Kirby ML, Van Mierop LHS, Teabeaut JR. Effects of the size of lesions of the cardiac neural crest at Effects of the size of lesions of the cardiac neural crest at
various embryologic ages on the incidence and type of various embryologic ages on the incidence
cardiac defects. Circulation 1986;73:360-4.

23 Kirby ML. Plasticity and predetermination of mesecephalic and trunk neural crest transplanted into the region of the cardiac neural crest. Dev Biol 1989;134:402-412.

24 Emanuel BS. Molecular cytogenetics: towards dissection of the contiguous gene syndromes. Am $\mathrm{f}$ Hum Genet 1988;43:575-8.

25 Lindsay EA, Halford S, Wadey R, Scambler PJ, Baldini A. Molecular cytogenetic characterisation of the DiGeorge syndrome region using fluorescence in situ hybridisation. Genomics (in press).

26 Halford S, Lindsay E, Nayudu M, Carey AH, Baldini A Scambler PJ. Low-copy-repeat sequences flank the DiGeorge/velo-cardio-facial syndrome loci at $22 \mathrm{q} 11$. Hum Mol Genet 1993;2:191-6.

27 Sambrook J, Fritsch EF, Maniatis T. Molecular cloning: laboratory manual. New York: Cold Spring Harbo Laboratory Press, 1989.

28 Feinberg A, Vogelstein B. A technique for radiolabeling DNA restriction endonuclease fragments to high specific radioactivity. Addendum. Anal Biochem 1984;137:266-7.

29 Estivill X, Farrall M, Scambler PJ, et al. A candidate for the cystic fibrosis locus isolated by selection for methylationfree islands. Nature 1987;326:840-5.

30 Perris R, Kratoski D, Bronner-Fraser M. Collagens in avian neural crest development: distribution in vivo and migration-promoting ability in vitro. Development 1991; 133:969-84.

31 Cheah KS, Lau ET, Au PKC, Tam PPL. Expression of the mouse alphal(II) collagen gene is not restricted to cartimouse alphal(II) collagen gene is not restricted to carti-

32 Wood A, Ashurst DE, Corbett A, Thorogood P. The transient expression of type II collagen at tissue interfaces transient expression of type II collagen at tissue interfaces
during mammalian craniofacial development. Development 1991;111:955-68. 